\section{Heterologous production of the lantibiotic Ala(0)actagardine in Escherichia coli $\dagger$}

\author{
Yanxiang Shi, Alejandro Bueno and Wilfred A. van der Donk* \\ Received 31st August 2012, Accepted 19th September 2012 \\ DOI: $10.1039 / \mathrm{c} 2 \mathrm{cc} 36336 \mathrm{~d}$
}

We report the heterologous production of Ala(0)actagardine in $E$. coli by co-expression of the substrate peptide GarA and its modification enzymes GarM and GarO. The activity of GarO, a luciferase-like monooxygenase that introduces the unique sulfoxide group of actagardine, was also investigated in vitro.

Lantibiotics are a class of ribosomally synthesized and posttranslationally modified peptides. ${ }^{1,2}$ They are characterized by the thioether-containing linkages lanthionine (Lan) and/or methyllanthionine (MeLan), originating from the dehydration of Ser/Thr residues in a precursor peptide (generically named LanA) followed by intramolecular Michael-type addition of Cys to the dehydrated residues. These dehydrations and cyclizations are catalyzed by modification enzymes that act on the C-terminal core region of the LanA peptide. An $\mathrm{N}$-terminal leader peptide is typically required for the modification of the core peptide (Fig. 1). Nisin, the best characterized lantibiotic, has been used as a food preservative to combat food-borne pathogens for more than forty years without the development of widespread antibiotic resistance. ${ }^{3}$ As such, lantibiotics are a promising group of compounds ${ }^{4}$ to battle the continuous rise of antibiotic resistance. ${ }^{5}$

Actagardine (originally isolated under the name gardimycin) ${ }^{6}$ is a 19-amino acid globular lantibiotic produced by Actinoplanes garbadinensis ATCC 31049 (Fig. 1). ${ }^{7,8} \mathrm{Ala}(0)$-actagardine is a natural variant with an additional $\mathrm{N}$-terminal alanine that is produced by Actinoplanes liguriae ATCC 31048. ${ }^{9}$ Actagardine possesses potent antimicrobial activity against gram-positive pathogens including Clostridium difficile and is stable in simulated gastric fluid. ${ }^{10}$ Actagardine inhibits cell wall biosynthesis by binding to lipid $\mathrm{II},{ }^{11}$ and its binding is not antagonized by vancomycin. $^{12}$ Deoxyactagardine $\mathrm{B}$ (DAB) is a structural analogue of actagardine, differing by two residues $(\mathrm{V} 15 \mathrm{~L}$ and I16V compared with actagardine) and the absence of the sulfoxide group. ${ }^{13}$ Compound NVB302, a semisynthetic derivative of DAB with a diaminoheptane tail attached to the

Department of Chemistry and Howard Hughes Medical Institute, University of Illinois at Urbana-Champaign, $600 \mathrm{~S}$ Mathews Ave, Urbana, IL 61801, USA. E-mail:vddonk@uiuc.edu;

Fax: + 1217244 8533; Tel: + 12172445360

$\dagger$ Electronic supplementary information (ESI) available: General experimental procedures, mass spectra, and bioassay results. See DOI: $10.1039 / \mathrm{c} 2 \mathrm{cc} 36336 \mathrm{~d}$

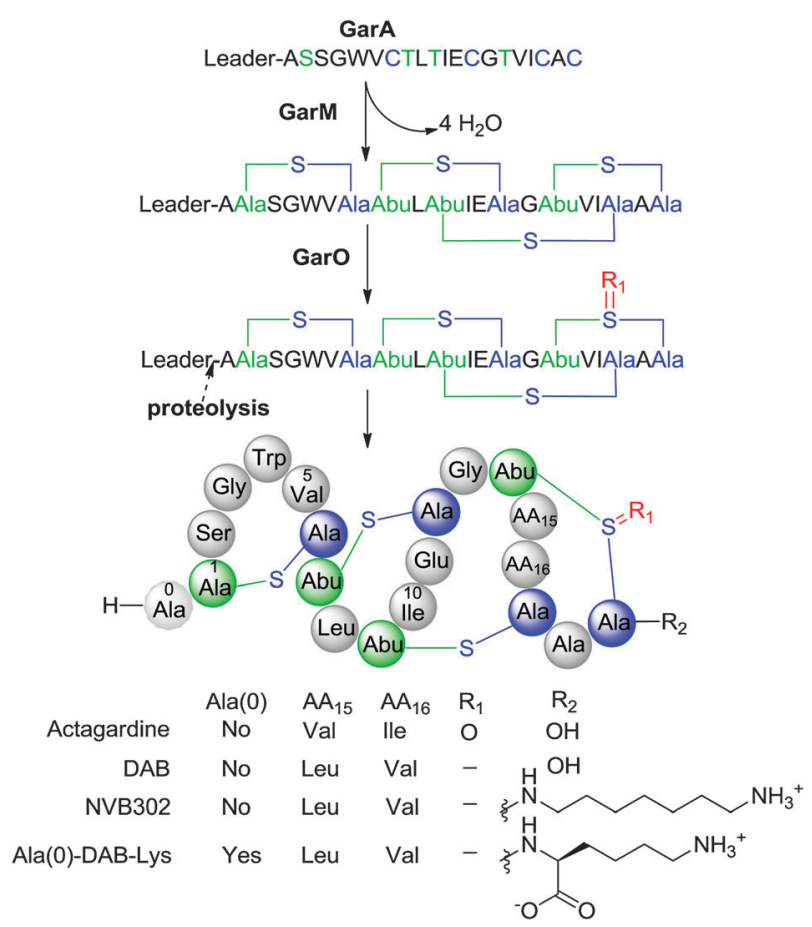

Fig. 1 Structures of actagardine, ${ }^{7}$ deoxyactagardine B (DAB), NVB302 and Ala(0)-deoxyactagardine B-Lys. The sequence of the leader peptide is MSALAIEKSWKDVDLRDGATSHPAGLGFGELTFEDLREDRTIYA.

C-terminus of DAB, has completed Phase I clinical trials for treatment of $C$. difficile-associated diarrhea.

The biosynthetic gene cluster of actagardine in A. garbadinensis ATCC 31049 was reported in 2009. In the cluster, gar $A$ encodes the precursor peptide, and gar $M$ encodes a bifunctional lanthionine synthetase that performs both the dehydration and cyclization of the core peptide (Fig. 1). The gene for a monooxygenase GarO is located downstream of gar $A$ and $\operatorname{gar} M$, and is expected to catalyze the formation of the sulfoxide group in actagardine on the basis of gene disruption studies. ${ }^{14}$

Actagardine and its derivatives have been produced by fermentation of Actinoplanes sp. or by heterologous expression in Streptomyces lividans. ${ }^{13,14}$ Based on the recent success in producing lanthionine-containing peptides in $E$. coli by co-expression of the substrate and corresponding modification enzymes, ${ }^{15-18}$ we set out to produce $\mathrm{Ala}(0)$ actagardine in $E$. coli. The genes encoding 
GarA, GarM and GarO were cloned from genomic DNA of A. garbadinensis ATCC 31049. Subsequently, gar $A$ and gar $M$ were inserted into the pRSFDuet-1 vector as a biscistronic construct (garA $/$ garM/pRSFDuet-1) encoding $\mathrm{N}$-terminally His $_{6}$-tagged GarA and wild type GarM. Two copies of the gar $O$ gene were inserted into the pCDFDuet-1 vector encoding proteins lacking an $\mathrm{N}$-terminal hexahistidine tag.

Co-expression of GarM and His $_{6}$-tagged GarA using the garA/garM/pRSFDuet-1 vector successfully generated four-fold dehydrated GarA. The peptide was purified by immobilized metal affinity chromatography (IMAC; $\mathrm{Ni}^{2+}$ ) and reversedphase high-performance liquid chromatography (RP-HPLC). After lyophilization, $4.2 \mathrm{mg}$ modified GarA was obtained from a $1 \mathrm{~L}$ culture. Proteolytic removal of the majority of the leader peptides with trypsin (cleavage after Arg-5 of the leader peptide) followed by treatment with aminopeptidase A8200 to remove residues -4 to -2 generated a product consistent with Ala(0)-deoxyactagardine (Fig. 2A). After incubation with 2-iodoacetamide (IAA), no IAA adducts were detected by matrix-assisted laser desorption ionization (MALDI) mass spectrometry (MS) (Fig. S1, ESI $\dagger$ ), suggesting that free cysteines were not present in the core peptide.

Ala(0)-deoxyactagardine (Ala(0)-DA) thus produced displayed low solubility. NVB302, which is under clinical development, contains a C-terminal 1,7-diaminoheptane tail, which increases solubility and bioactivity compared with deoxyactagardine. ${ }^{19}$ In order to produce a structure similar to NVB302, we substituted Val15 and Ile16 in GarA with Leu and Val, respectively, and introduced a lysine residue at its $\mathrm{C}$-terminus, forming GarA-V15L/I16V/19insK (Fig. 1) to similarly increase the solubility of Ala(0)-DA produced in E. coli. The dehydration and cyclization of this mutant GarA by GarM were not affected by these mutations or by the addition of the C-terminal lysine as confirmed by MALDI MS after proteolytic cleavage (Fig. 2B). The compound produced was termed Ala(0)-DABLys (Fig. 1).

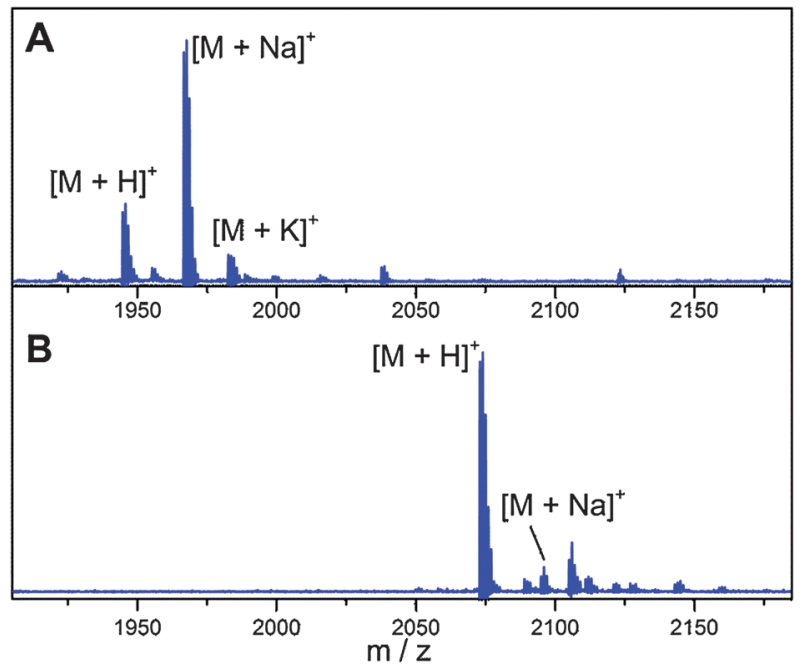

Fig. 2 MALDI-MS spectra of GarA modified by GarM in E. coli and treated with trypsin and aminopeptidase A8200 to remove the leader peptide. (A) Spectrum of Ala(0)-deoxyactagardine, $[\mathrm{M}+\mathrm{H}]^{+}$ calculated $m / z$ : 1945.34, observed $m / z: 1945.68$; (B) spectrum of Ala(0)-DAB-Lys, $[\mathrm{M}+\mathrm{H}]^{+}$calc. $m / z$ : 2073.51, obsv. $m / z$ : 2074.01 .

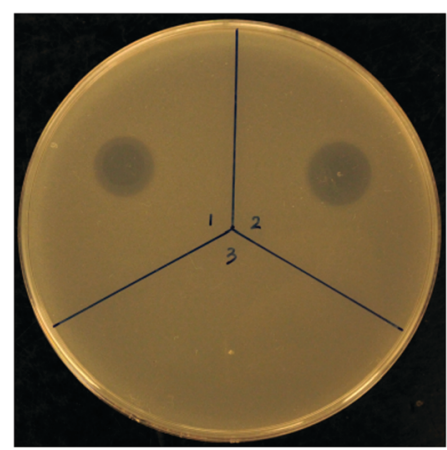

Fig. 3 Antimicrobial assays of Ala(0)-DAB-Lys modified in E. coli. (1) Nisin, (2) Ala(0)-DAB-Lys from GarA/GarM coexpression in E. coli, (3) negative control containing buffer and proteinases. The applied samples in (1) and (2) consisted of $20 \mu \mathrm{L}$ of $100 \mu \mathrm{M}$ stock solutions.

To confirm that the product had the correct ring topology, it was analyzed by tandem MS indicating a globular structure as no fragments were generated from the C-terminal fourteen amino acid region (Fig. S2, ESI $\dagger$ ). Furthermore, Ala(0)-DABLys displayed antimicrobial activity against Bacillus subtilis W23, Microccoccus luteus 4698 (Fig. 3 and Fig. S3, ESI $\dagger$ ), and Enterococcus faecalis 29212. The MIC of Ala(0)-DAB-Lys against E. faecalis was $7.3 \mu \mathrm{M}$ compared to $4.2 \mu \mathrm{M}$ reported for deoxyactagardine. ${ }^{14}$ Thus, the addition of the C-terminal lysine largely maintained the antimicrobial activity of $\mathrm{Ala}(0)$ deoxyactagardine, while significantly increasing solubility.

Deoxyactagardine is less active than actagardine against some bacterial strains with a two-fold increased MIC for inhibition of the growth of M. luteus $4698 .{ }^{14}$ In an attempt to produce sulfoxide-containing analogs, co-expression of the monooxygenase $\mathrm{GarO}$ was pursued. Two systems were evaluated in which either the garA/garM/pRSFDuet-1 plasmid was used in combination with a $P C D F D u e t-1$ vector containing two copies of garO or the $\operatorname{garO}$ gene was inserted into the garA/garM/ pRSFDuet-1 plasmid (see ESI $\dagger$ ). His 6 -tagged GarA was purified by IMAC followed by $\mathrm{C} 8$ solid phase extraction (SPE). The purified product was incubated with trypsin and aminopeptidase to remove the leader peptide and the product was analyzed by MALDI-MS. For both approaches, the mass of the resulting fourfold dehydrated core peptide was increased by $16 \mathrm{Da}$ (Fig. 4A and Fig. S4, ESI $\dagger$ ), consistent with the formation of one sulfoxide group. Unfortunately, when the same experiments were performed with GarA-V15L/I16V/19insK, the GarO-mediated oxidation was incomplete (Fig. S5, ESI $\dagger$ ), suggesting that the additional C-terminal Lys interferes with efficient oxidation.

Actagardine is the only lantibiotic containing a sulfoxide group. To investigate the GarO enzymatic activity in vitro, garO was cloned into a pET28b vector. The protein was expressed in E. coli with an N-terminal $\mathrm{His}_{6}$-tag, and was purified by IMAC. His $_{6}$-GarO behaved as a monomer in solution as determined by analytical gel filtration chromatography (Fig. S6, ESI $\dagger$ ). Sequence analysis suggests that GarO is a luciferase-like monooxygenase that possesses a typical binding domain for flavin mononucleotide (FMN). Previous studies on luciferase-like enzymes ${ }^{20,21}$ have shown that reduced FMN reacts with molecular oxygen, forming a flavin-hydroperoxide, 


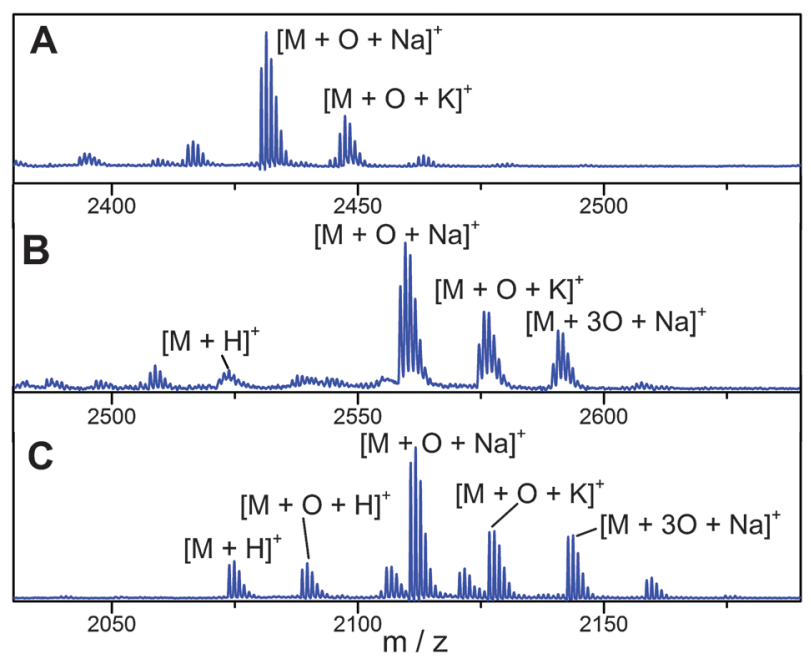

Fig. 4 MALDI-MS spectra of GarA modified by GarM and GarO. (A) Spectrum of GarA co-expressed with GarM and GarO in E. coli and treated with trypsin, $\mathrm{M}$ indicates GarM-modified GarA treated with trypsin, $[\mathrm{M}+\mathrm{O}+\mathrm{Na}]^{+}$calc. $m / z$ : 2431.06, obs. $m / z$ : 2431.45 ; (B) product of incubation of GarA-V15L/I16V/19insK with GarO in vitro and subsequent trypsin digest; $[\mathrm{M}+\mathrm{O}+\mathrm{Na}]^{+}$calc. $m / z$ : 2559.23, obs. $m / z$ : 2559.55; (C) product of incubation of purified Ala(0)-DAB-Lys with GarO in vitro, $\mathrm{M}$ indicates Ala(0)-DAB-Lys, $[\mathrm{M}+\mathrm{O}+\mathrm{Na}]^{+}$calc. $m / z: 2111.49$, obs. $m / z: 2111.77$.

which is followed by transfer of an oxygen atom to the substrate. NAD $(\mathrm{P}) \mathrm{H}$ then commonly reduces the oxidized flavin back to its reduced form. We incubated GarM-modified GarA and GarA-V15L/I16V/19insK with purified GarO, FMN, and NADH, followed by proteolytic removal of the leader peptide as described above. MALDI analysis showed the formation of a molecular ion consistent with a single oxidation in the core peptide (Fig. 4B). Substitution of NADH with NADPH resulted in abolishment of the GarO activity.

The dehydration and cyclization reactions involved in lantibiotic biosynthesis require the presence of the leader peptide, but other tailoring-type transformations such as hydroxylation ${ }^{16}$ and oxidative decarboxylation ${ }^{22}$ do not require the leader peptide to be attached. To determine whether oxidation by GarO required the leader peptide, the enzyme was incubated for $8 \mathrm{~h}$ with purified Ala(0)-DAB-Lys, FMN, and NADH. The major product was a peptide with $m / z$ of +16 Da (Fig. 4C). The addition of $16 \mathrm{Da}$ occurs in the region of the three intertwined-rings of the product as shown by tandem mass spectrometry (Fig. S2, ESI $\dagger$ ), consistent with the reported structure of actagardine. Thus, the leader peptide is not required for GarO catalysis. A peak corresponding to the addition of three oxygen atoms was also observed in the product of in vitro GarO modification. This product is likely the result of uncoupling of the formation of the flavin peroxide and the oxygen transfer to the substrate, resulting in the formation of hydrogen peroxide or superoxide, which are known general side products of in vitro reactions with flavin-dependent monooxygenases. ${ }^{23}$ Hydrogen peroxide formation in turn results in non-enzymatic oxidation of the thioether rings.

In summary, by coexpression of the GarA precursor peptide and its modification enzyme GarM in E. coli, dehydrated and cyclized Ala(0)-deoxyactagardine was produced after proteolytic treatment. Introduction of a lysine residue at the $\mathrm{C}$-terminus of $\mathrm{Ala}(0)$-deoxyactagardine $\mathrm{B}$ generated a derivative with increased solubility and comparable bioactivity. This methodology may present an alternative route to actagardine analogs. The activity of GarO monooxygenase in the actagardine biosynthesis cluster was demonstrated in E. coli and in vitro. The enzyme was active in the absence of the GarA leader peptide.

This work was supported by the National Institutes of Health (GM58822 to W.A.V.).

\section{Notes and references}

1 P. J. Knerr and W. A. van der Donk, Annu. Rev. Biochem., 2012, 81, 479.

2 G. Bierbaum and H. G. Sahl, Curr. Pharm. Biotechnol., 2009, 10, 2.

3 J. Lubelski, R. Rink, R. Khusainov, G. N. Moll and O. P. Kuipers, Cell. Mol. Life Sci., 2008, 65, 455.

4 P. D. Cotter, C. Hill and R. P. Ross, Curr. Protein Pept. Sci., 2005, 6, 61 .

5 M. A. Fischbach and C. T. Walsh, Science, 2009, 325, 1089.

6 S. Somma, W. Merati and F. Parenti, Antimicrob. Agents Chemother., 1977, 11, 396.

7 N. Zimmermann, J. W. Metzger and G. Jung, Eur. J. Biochem., 1995, 228, 786.

8 A. Malabarba, M. Landi, R. Pallanza and B. Cavalleri, J. Antibiot., 1985, 38, 1506.

9 L. Vértesy, W. Aretz, A. Bonnefoy, E. Ehlers, M. Kurz, A. Markus, M. Schiell, M. Vogel, J. Wink and H. Kogler, J. Antibiot., 1999, 52, 730 .

10 S. Donadio, S. Maffioli, P. Monciardini, M. Sosio and D. Jabes, Appl. Microbiol. Biotechnol., 2010, 88, 1261.

11 Y. Héchard and H. G. Sahl, Biochimie, 2002, 84, 545.

12 H. Brötz, G. Bierbaum, K. Leopold, P. E. Reynolds and H. G. Sahl, Antimicrob. Agents Chemother., 1998, 42, 154.

13 S. Boakes, A. N. Appleyard, J. Cortes and M. J. Dawson, J. Antibiot., 2010, 63, 351.

14 S. Boakes, J. Cortes, A. N. Appleyard, B. A. M. Rudd and M. J. Dawson, Mol. Microbiol., 2009, 72, 1126.

15 Y. Shi, X. Yang, N. Garg and W. A. van der Donk, J. Am. Chem. Soc., 2011, 133, 2338.

16 A. Ökesli, L. E. Cooper, E. J. Fogle and W. A. van der Donk, J. Am. Chem. Soc., 2011, 133, 13753.

17 N. Garg, W. Tang, Y. Goto and W. A. van der Donk, Proc. Natl. Acad. Sci. U. S. A., 2012, 109, 5241.

18 W. Tang and W. A. van der Donk, Biochemistry, 2012, 51, 4271.

19 M. J. Dawson, A. N. Appleyard, J. Cortes Bargallo and S. N. Wadman, Actagardine Derivatives, and Pharmaceutical Use Thereof, $\mathrm{WO} / 2011 / 095769,2011$.

20 W. J. H. van Berkel, N. M. Kamerbeek and M. W. Fraaije, J. Biotechnol., 2006, 124, 670.

21 R. Boden, E. Borodina, A. P. Wood, D. P. Kelly, J. C. Murrell and H. Schaefer, J. Bacteriol., 2011, 193, 1250.

22 T. Kupke, C. Kempter, G. Jung and F. Götz, J. Biol. Chem., 1995, 270, 11282.

23 S. K. Krueger and D. E. Williams, Pharmacol. Ther., 2005, 106, 357. 